\title{
Safety, tolerability and risk benefit analysis of tiotropium in COPD
}

\author{
Yuji Oba \\ Tareq Zaza \\ Danish MThameem \\ University of Missouri, School \\ of Medicine, Division of Pulmonary, \\ Critical Care and Environmental \\ Medicine, Columbia, MO, USA
}

\begin{abstract}
COPD is a chronic disease and, like many other chronic diseases, there is no treatment to reverse the severity of the disease except for lung transplant. To date, no inhaled medications have been shown to improve survival. Tiotropium bromide is a long-acting inhaled anticholinergic drug for the treatment of COPD that can improve lung function, reduce symptoms and exacerbations, and improve quality of life with once-daily dosing. It was initially approved and marketed in several countries in Europe in 2002 and then approved in the US in 2004. Tiotropium is generally well tolerated with dry mouth being the main adverse effect. Other adverse effects include constipation, tachycardia, blurred vision, urinary retention and increased intraocular pressure. Despite the recently raised concerns about an excess risk of cardiovascular adverse events with inhaled anticholinergic agents, the risk/benefit ratio of tiotropium appears still favorable given the favorable safety profile demonstrated in the UPLIFT study. However, caution should be advised in patients at high risk for cardiovascular disease given the paucity of data in such patients.
\end{abstract}

Keywords: lung diseases, obstructive, bronchodilator agents, tiotropium bromide

\section{Management issues in treating COPD}

COPD is a chronic disease and, like many other chronic diseases, there is no treatment to reverse the severity of the disease except for lung transplant. COPD is the fourth leading cause of death in the US and is expected to be the third by 2020. The prevalence of COPD is on the increase globally with an attendant increase in morbidity and mortality.

Despite the recent advances in understanding of the disease and its management, only a few therapies can have an impact on mortality in patients with stable COPD. These therapies include smoking cessation (Anthonisen et al 2005), continuous oxygen therapy for hypoxemic patients (Nocturnal Oxygen Therapy Trial Group 1980; Medical Research Council Working Party 1981), influenza vaccination (Nichol et al 1999), and lung reduction surgery for selected patients (Fishman et al 2003).

Pharmacotherapy for COPD has been used to alleviate symptoms, prevent exacerbations, and improve exercise capacity and quality of life. However, to date no inhaled medications have been shown to improve survival. The international guidelines developed by Global Initiative for Chronic Obstructive Lung Disease currently set the standard of care (Rabe et al 2007) and long-acting bronchodilators are considered as the first-line maintenance therapy in patients with moderate to severe COPD.

The US Food and Drug Administration (FDA) recently issued a black box warning to long-acting beta agonists (LABAs) for asthma to alert healthcare professionals and patients that these medicines may increase the chance of severe asthma episodes and death (FDA 2005). Although information is not available for similar concerns applicable to patients with COPD, caution may be advised given the relatively high prevalence of reversible component in patients with very severe COPD and exclusion of such patients in most clinical trials.

A recent observational study of a cohort of 175,906 elderly COPD patients found that the use of inhaled corticosteroids (ICSs) was associated with a dose-dependent 
increase in hospitalization with pneumonia followed by death within 30 days (Ernst et al 2007).

Combination therapy with a LABA with an ICS reduces COPD-related hospitalizations in patients with moderate to severe COPD and is the only pharmacotherapy that has been shown to alter the decline in lung function, which is a hallmark of the disease (Calverley et al 2007). Further studies are needed to determine whether this combination might increase the number of adverse side effects given recently raised concerns with LABAs and ICSs.

Tiotropium bromide (Boehringer Ingelheim, Ingelheim, Germany) is a long-acting inhaled anticholinergic agent for the treatment of COPD that can improve lung function, reduce symptoms and COPD-related hospitalizations, and improve quality of life with once-daily dosing. The results of some studies have suggested that tiotropium is more effective than LABAs in reducing COPD-related hospitalizations and improving quality of life (Brusasco et al 2003; Oba 2007). Tiotropium was initially approved and marketed in several countries in Europe in June 2002 and then in the US in early 2004.

Two recently published studies have raised concerns for a possible increase in mortality and cardiovascular events with the use of inhaled anticholinergics. In a nested case-control study of a cohort of 32,120 COPD patients and 320,501 control participants, ipratropium bromide (Boehringer Ingelheim, Ingelheim, Germany) was associated with an increased risk for mortality, whereas ICSs appeared to reduce the risk for death (Lee et al 2008). In a 17-trial meta-analysis, the use of inhaled anticholinergics (ipratropium and tiotropium) was associated with an increased risk for a composite of myocardial infarction (MI), stroke and cardiovascular death (Singh et al 2008).

Although recent guidelines have advocated the use of inhaled anticholinergics for disease control (Rabe et al 2007), there has been a growing concern in the clinical community that inhaled anticholinergics might increase the risk for cardiovascular events and mortality as describe above. This review examines the safety, tolerability and risk/benefit ratio of a long-acting anticholinergic agent, tiotropium bromide.

\section{Overview of pharmacology of tiotropium and short- and long-acting bronchodilators Short- and long-acting bronchodilators}

Short-acting beta- 2 agonists act directly upon bronchial smooth muscle causing the airways to dilate for up to 6 hours. In turn, this improves 'smooth muscle dependent' outcome parameters such as symptoms and airway caliber (Sestini et al 2003).

The prime action of beta-adrenergic drugs is to stimulate adenyl cylase, the enzyme that catalyzes the formation of cyclic-3, 5-adenosine monophosphate from adenosine triphosphate.

Similar to short-acting agents, LABAs act directly upon beta-2 adrenoreceptors, causing smooth muscle to relax and airways to dilate. Both salmeterol (GlaxoSmithKline, Brentford, UK) and formoterol (Foradil ${ }^{\circledR}$, Novartis Pharma AG, Basel, Switzerland) are relatively lipophilic, which may in part explain their prolonged duration of action.

Salmeterol interacts with both the active site and an exosite of the beta- 2 adrenoreceptor, and the molecular basis of this interaction is termed the salmeterol hinge (charniere) theory (Pauwels et al 2001; Celli and MacNee 2004). Formoterol is partially lipophilic and forms a membrane depot. Formoterol has a more rapid onset of action than salmeterol (National Collaborating Centre for Chronic Conditions 2004).

The onset of action for both short- and long-acting beta-2 agonist is 5 to $15 \mathrm{~min}$. Effects of short-acting agents usually last only 4 to 6 hours whereas those of LABAs last 12 hours.

\section{Short- and long-acting anticholinergics}

The characteristic airflow obstruction in COPD is multifactorial in origin and in part due to potentially reversible high cholinergic tone (Gross and Skorodin 1984; Chapman et al 1990). Moreover, vagally mediated mechanisms are also implicated in enhanced submucosal gland secretion in patients with COPD (Dahl et al 2001).

Short-acting anticholinergics such as ipratropium (with a duration of action of 3 to 6 hours) offset high resting bronchomotor tone to relax smooth muscle with subsequent improvement in airway caliber (Mahler et al 1999; Dahl et al 2001; Rennard et al 2001).

Three main subtypes (M1, M2 and M3) of muscarinic receptors exist. The activation of both $\mathrm{M} 1$ and $\mathrm{M} 3$ receptors results in bronchoconstriction whereas the $\mathrm{M} 2$ receptor is protective against such an effect.

In contrast to ipratropium, tiotropium dissociates rapidly from the M2 receptor (therefore minimizing the loss of any putative benefit) and dissociates only slowly from the M3 receptor (Disse et al 1993). This in turn causes a reduction in resting bronchomotor tone, smooth muscle to relax and airways to dilate for a greater length of time. The prolonged duration of action of tiotropium therefore facilitates oncedaily administration with potential concordance benefits. 
The peak onset of bronchodilation with tiotropium occurs between 1 to 3 hours with improvements in $\mathrm{FEV}_{1}$ persisting for over 24 hours (Barnes et al 2000). In a pharmacodynamic study, it was discovered that $90 \%$ of the improvement in $\mathrm{FEV}_{1}$ was achieved within 24 hours of first inhalation of tiotropium, while ongoing improvements in forced vital capacity were expected beyond 1 week of regular treatment (van Noord et al 2002).

\section{Tolerability}

Inhaled LABAs are generally well tolerated although adverse effects such as fine tremor and palpitations are occasionally troublesome. These agents should be used in caution in patients with cardiovascular disease, at risk of developing prolongation of the QT interval and in whom concomitant drug administration may increase the risk of serious hypokalaemia (Salpeter et al 2004).

Tiotropium is generally well tolerated and poorly absorbed from the gastrointestinal tract, but as with all inhaled anti-cholinergic agents, care should be taken in patients with glaucoma and prostatic hyperplasia. In clinical trials comparing tiotropium with placebo, the frequency of dry mouth, constipation, and urinary tract infection appears to increase with patient age. Further details are described in the following section.

It is also important to point out that no tachyphylaxis to its bronchodilatory effect has been observed with tiotropium (Casaburi et al 2000), a phenomenon that is known to occur with LABAs (Donohue et al 2003).

\section{Safety and tolerability of tiotropium Comparison with placebo}

Tiotropium was generally well tolerated in randomized clinical trials which ranged from 2 to 12 months (Casaburi et al 2002; Brusasco et al 2003; Niewoehner et al 2005; Dusser et al 2006; Verkindre et al 2006; Chan et al 2007; Criner et al 2008). In all studies, the completion rate was higher with tiotropium (77\%-98\%) than with placebo (71\%-92\%). The most commonly cited reason for withdrawal was worsening of COPD or adverse events. The completion rate in a recently published 4-year randomized controlled trial involving 5993 patients (UPLIFT, Understanding Potential Long-Term Impacts on Function with Tiotropium; Tashkin et al 2008) was significantly higher with tiotropium than with placebo (63\% vs 55\%, p < 0.0001). The most common reason for withdrawal in the UPLIFT study was adverse events.

We conducted a pooled analysis to examine the incidence of serious adverse events (SAEs) and all-cause mortality using the same methods as in a recent meta-analysis by Singh et al. Ten randomized control trials reported incidence of SAEs (Casaburi et al 2000, 2002, 2005; Covelli et al 2005; Niewoehner et al 2005; Chan et al 2007; Criner et al 2008; Moita et al 2008; Tashkin et al 2008; Voshaar et al 2008) and 11 trials reported all-cause mortality (Casaburi et al 2000, 2002, 2003, 2005; Niewoehner et al 2005; Chan et al 2007; Powrie et al 2007; Criner et al 2008; Moita et al 2008; Tashkin et al 2008; Voshaar et al 2008). There was no difference in all-cause mortality between the tiotropium and placebo recipients when all reported results were combined (odds ratio [OR] 0.94; 95\% confidence interval [CI] 0.82-1.08). However, the incidence of SAEs was significantly lower in the tiotropium recipients (OR 0.88; 95\% CI 0.81-0.96). (Figure 1) The most frequently reported SAEs were respiratory events such as COPD exacerbation or pneumonia (Casaburi et al 2005; Covelli et al 2005; Niewoehner et al 2005; Criner et al 2008; Tashkin et al 2008). The incidence of discontinuation due to adverse events was significantly lower with tiotropium than with placebo $(21 \%$ vs $25 \%, \mathrm{p}<0.0001$ ) in the UPLIFT study (Tashkin et al 2008) as well as in a pooled analysis conducted by us (OR 0.79; 95\% CI 0.71-0.88) (Figure 2).

The causes of death were consistent with what might be expected in the patient population. In a meta-analysis, pulmonary mortality was non-significantly lower with tiotropium than with placebo (OR 0.5; 95\% CI 0.19-1.29) (Barr et al 2006). Cardiovascular (OR 1.17; 95\% CI 0.54-2.51) and cancer mortality (OR 0.77; 95\% CI 0.28-2.12) were similar in the tiotropium and placebo recipients.

There has been a growing concern in the clinical community that inhaled anticholinergics might increase the risk for cardiovascular adverse events. Although tiotropium was approved by FDA in 2004, the Pulmonary and Allergy Drugs Advisory Committee of the agency concerned about suggestions of increased cardiovascular risk when pivotal clinical trials were reviewed (FDA 2002). Barr et al (2006) conducted a meta-analysis in 2006 in which the frequency of arrhythmia was significantly higher with tiotropium than with placebo when adjusted for statistical heterogeneity (OR 2.33; 95\% CI 1.11-4.88).

In March 2008, The FDA issued a warning about a potential increased risk of stroke in patients using tiotropium (FDA 2008). Boehringer Ingelheim, the manufacturer of tiotropium, reported to the agency a preliminary estimate that the risk of stroke during 29 clinical trials was 8 patients per 1000 patients treated for 1 year with tiotropium and 6 patients per 1000 patients treated with placebo for the same 


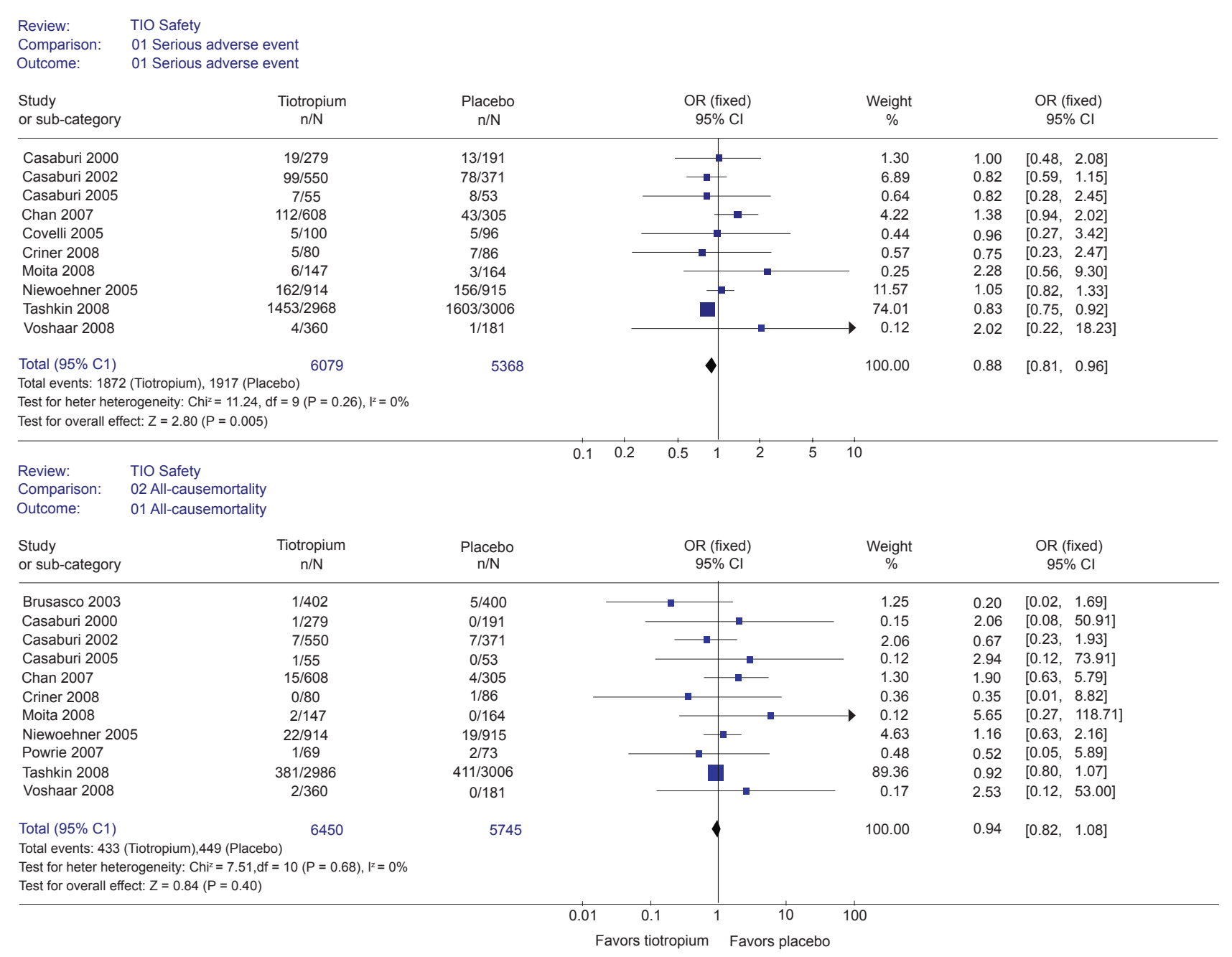

Figure I Summary effects of tiotropium on serious adverse events and all-cause mortality.

Abbreviations: $\mathrm{Cl}$, confidence interval; $\mathrm{OR}$, odds ratio.

Review: TIO Safety

Comparision: 04 Withdrawals due to adverse events

Outcome: $\quad 01$ Withdrawals due to adverse events

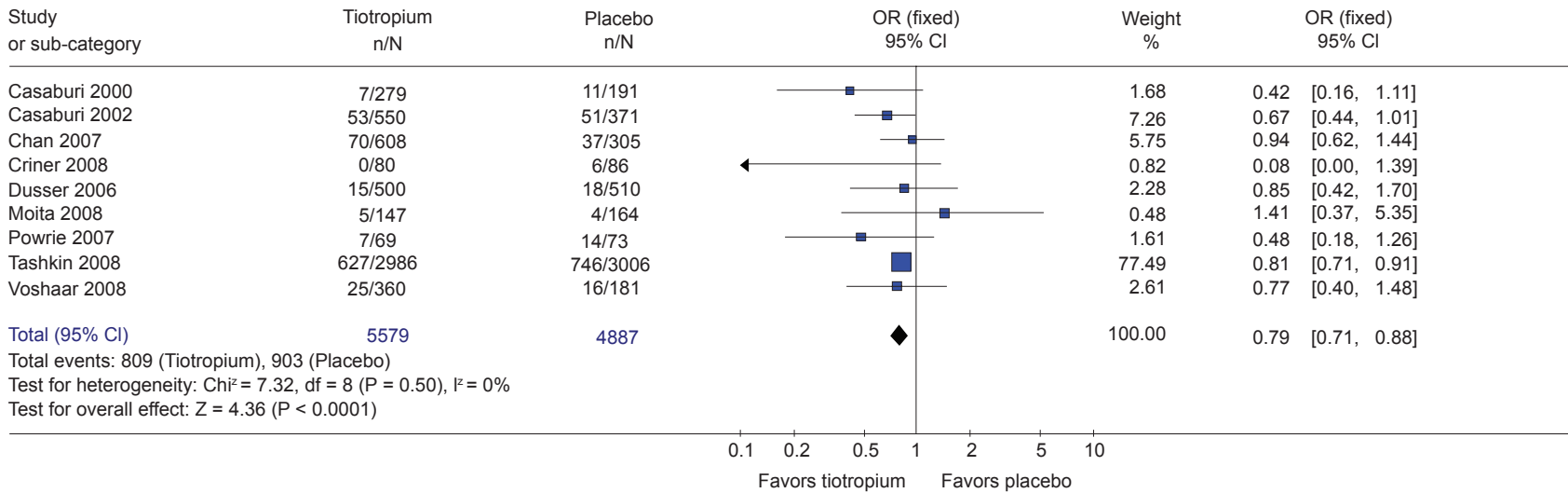

Figure 2 Forest plot examining the incidence of discontinuation due to adverse events with tiotropium vs placebo including the UPLIFT study. Abbreviations: $\mathrm{Cl}$, confidence interval; OR, odds ratio. 
amount of time. In these trials, which included approximately 13,500 patients with COPD, the estimated excess risk of any type of stroke caused by tiotropium was 2 patients for each 1000 patients using tiotropium for 1 year. The FDA cautioned practitioners that the findings were only preliminary and no regulatory action had been taken at that time.

After the FDA warning, two major studies were published concerning the possible association between inhaled anticholinergics and elevated risk for all-cause mortality and cardiovascular events. One study, which was a nested case-control study with a cohort of 32,120 case patients and 320,501 control participants, showed that ipratropium was associated with an increased risk for mortality in patients with COPD, whereas inhaled corticosteroids appeared to reduce the risk for death (Lee et al 2008). The use of ipratropium was associated with a higher risk of all-cause mortality (OR 1.11; 95\% CI 1.08-1.15) and a $34 \%$ increase (95\% CI $22 \%-47 \%$ ) in the risk for cardiovascular death, whereas ICSs and LABAs both reduced the risk for all-cause mortality by $20 \%$ and $8 \%$. ICSs were also associated with a $20 \%$ decrease (95\% CI 12\%-28\%) in the risk for cardiovascular death (Lee et al 2008).

The other study was a 17-trial meta-analysis, in which the use of inhaled anticholinergics (ipratropium and tiotropium), compared with control (placebo or comparator), was associated with an increased risk for a composite of MI, stroke and cardiovascular death (Singh et al 2008). The use of inhaled anticholinergics in patients with COPD was associated an increase risk for MI with a number needed to harm of 174 per year and an increased risk for cardiovascular death with a number needed to harm of 40 per year. The authors concluded that clinician should closely monitor patients with COPD who were receiving an inhaled anticholinergic agent.

Soon after the above two studies were published, the manufacturer reported the results of the UPLIFT study, which is a large 4-year, randomized, placebo-controlled, double-blind trial of tiotropium in patients with moderate to severe COPD conducted at 490 centers in 37 courtiers involving 5993 patients (Tashkin et al 2004). The UPLIFT study provided additional long-term safety data and additional insight into the risk of stroke or other safety findings of tiotropium.

Tiotropium showed a trend toward reduced mortality (14.9\% vs 16.5\%, hazard ratio [HR] 0.89; 95\% CI 0.79-1.02 ). The incidence of adverse events (92.6\% vs $92.3 \%$ ) and the proportion of SAEs $(51.6 \%$ vs $50.2 \%$ ) were similar in the tiotropium and placebo group. Cardiovascular adverse events were significantly less with tiotropium (relative risk [RR]
$0.84 ; 95 \%$ CI $0.73-0.98)$. The incidence of MI was also less with tiotropium (RR 0.71; 95\% CI 0.52-0.99). There were 82 strokes among the 2987 patients (2.7\%) taking tiotropium and 80 strokes among the 3006 patients (2.7\%) taking placebo. The difference was not statistically significant.

We reanalyzed the meta-analysis conducted by Singh et al (2008) incorporating the results of UPLIFT study to further investigate the possible association between tiotropium and increased risk of cardiovascular events. The association between inhaled anticholinergics (ipratropium and tiotropium) and increased risk for a composite of $\mathrm{MI}$, stroke and cardiovascular death became no longer significant with the use of tiotropium (Figures $3 a, b$ ).

We also found the following errors in the meta-analysis by Singh et al (2008): 1) The number of the control group in the study by Chan et al was 305 instead of 350 (Chan et al 2007). 2) The incidence of serious cardiovascular events in the study by Wedzicha et al was 34 with tiotropium and 23 with placebo instead of 23 and 13 (Wedzicha et al 2008). 3) The study by Donohue et al (2002) should have been excluded since Brusasco et al (2003) reported combined results of the study by Donohue et al and another unpublished study (Barr 2004). Although these errors did not affect the results, they were corrected in our pooled analysis.

The difference in the cardiovascular events in the Singh's study was primarily derived from long-term studies (ie, duration of study $>6$ months). We found evidence of possible publication bias when the long-term studies were analyzed with a funnel plot (Figure 4) and a statistical test (Horbold-Egger: bias $=0.722318[92.5 \% \mathrm{CI}=0.450252-0.994383] \mathrm{p}=0.003)$. The difference in the cardiovascular events detected in the Singh's study could be due to publication bias. The FDA is currenlty reconsidering its recent warning that tiotropium might raise stroke risk as of October 10, 2008. The FDA said it would take several months for it to finish its review of the huge amount of data from the UPLIFT study.

The adverse event data indicated that anticholinergic effects were more frequent with tiotropium (FDA 2002; Barr et al 2006). Dry mouth was by far the most common with an incidence of $16 \%$ with tiotropium and $2.7 \%$ with placebo (Casaburi et al 2002) and more frequent in women and older patients (FDA 2002). The peak incidence has been reported to occur after 3 to 4 weeks of therapy, when steadystate concentrations are reached. Dry mouth was generally mild and resolved during treatment in most patients and less than $1 \%$ of the patients withdrew from the clinical studies as a result (Casaburi et al 2002, 2003; Vincken et al 2002). Other anticholinergic effects included constipation and 
Review: TIO Safety

Comparison: 03 Composite cardiovascular events

Outcome: $\quad 02$ All studies

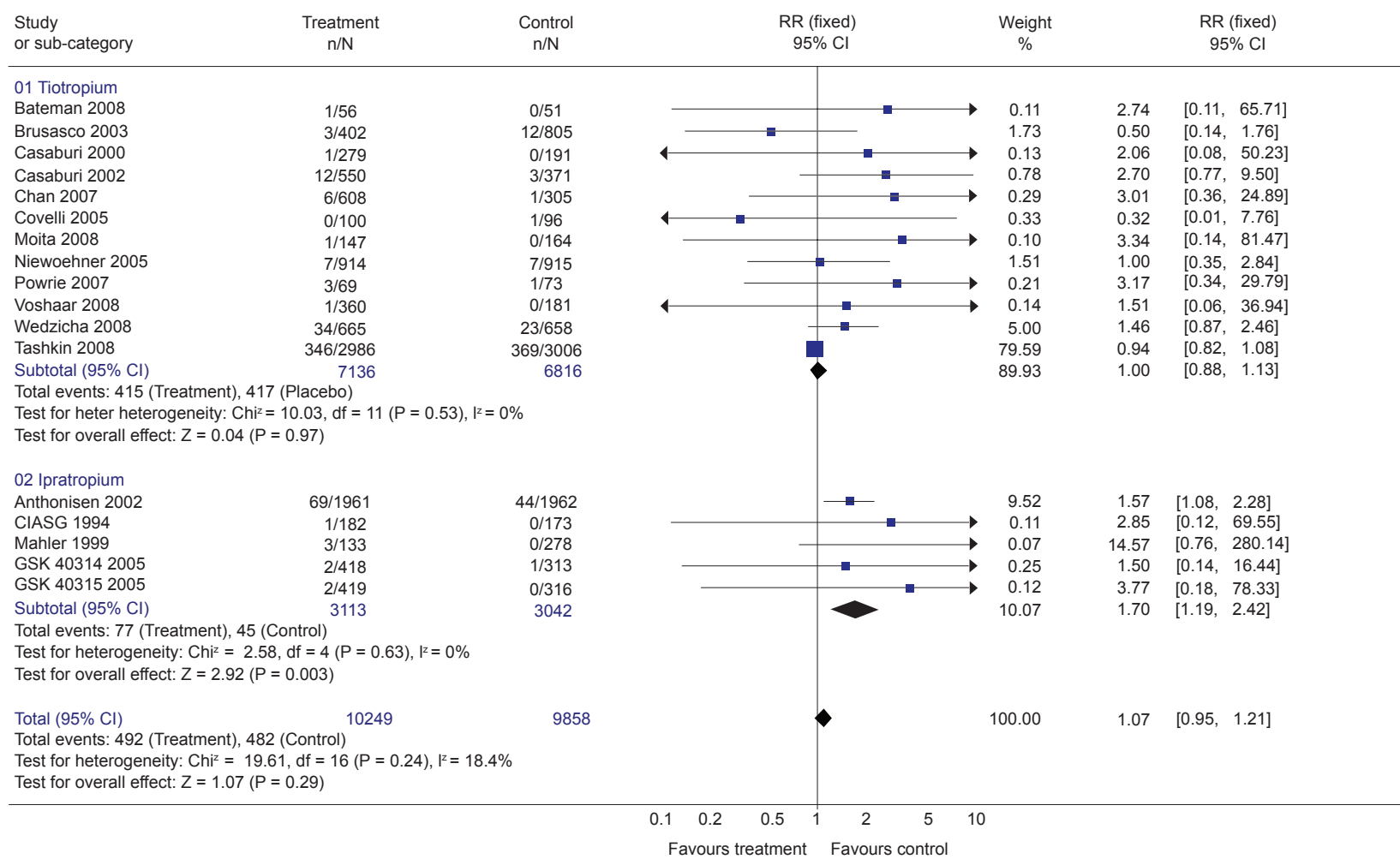

Figure 3a Forest plot examining the incidence of composite cardiovascular events with anticholinergics vs control.All studies (short and long term) including UPLIFT study. Abbreviations: $\mathrm{Cl}$, confidence interval; $\mathrm{RR}$, relative risk.

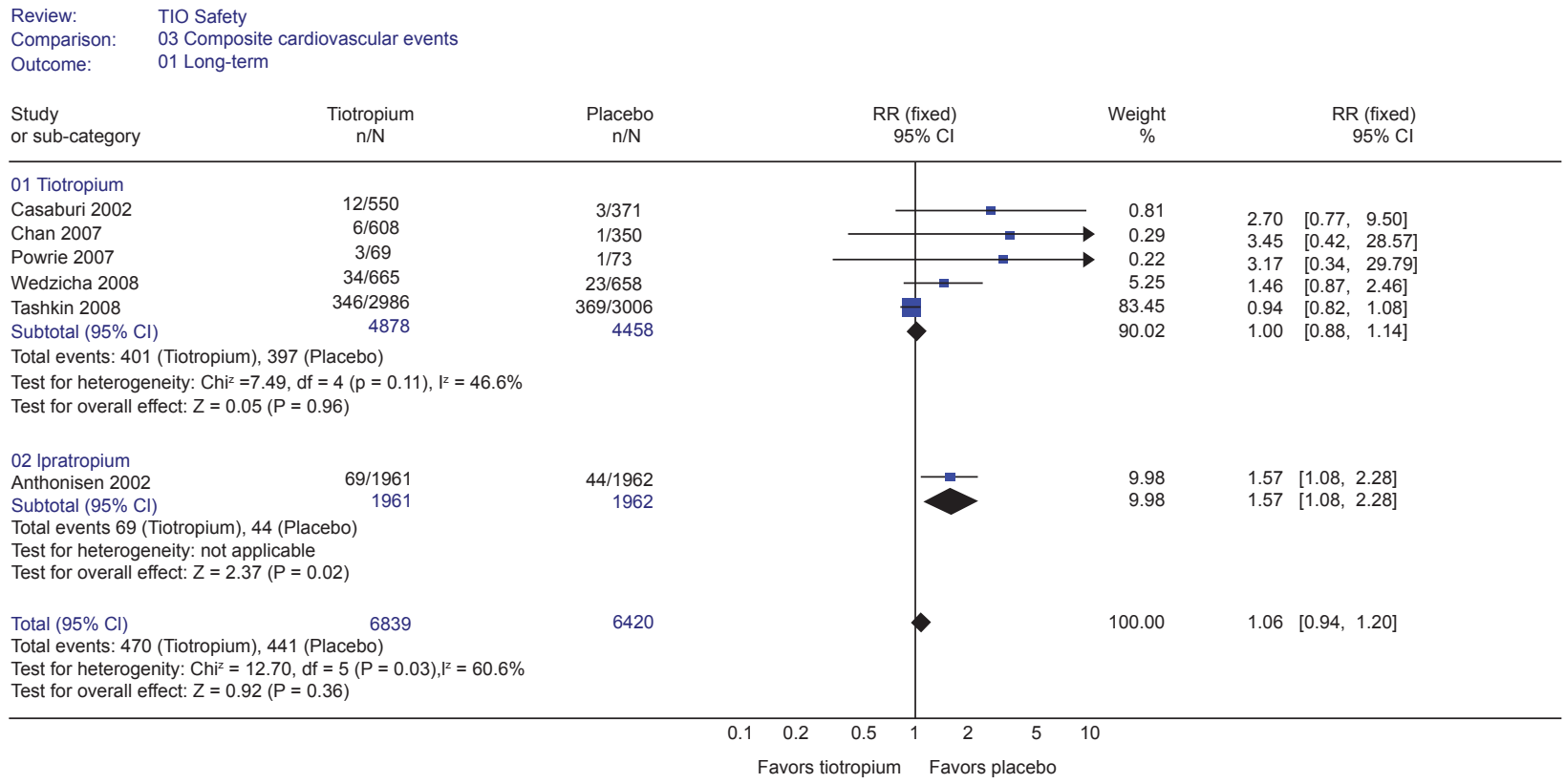

Figure 3b Forest plot examining the incidence of composite cardiovascular events with anticholinergics vs control. Long-term trials ( $\geq 6$ months) including UPLIFT study. Abbreviations: $\mathrm{Cl}$, confidence interval; $\mathrm{RR}$, relative risk. 


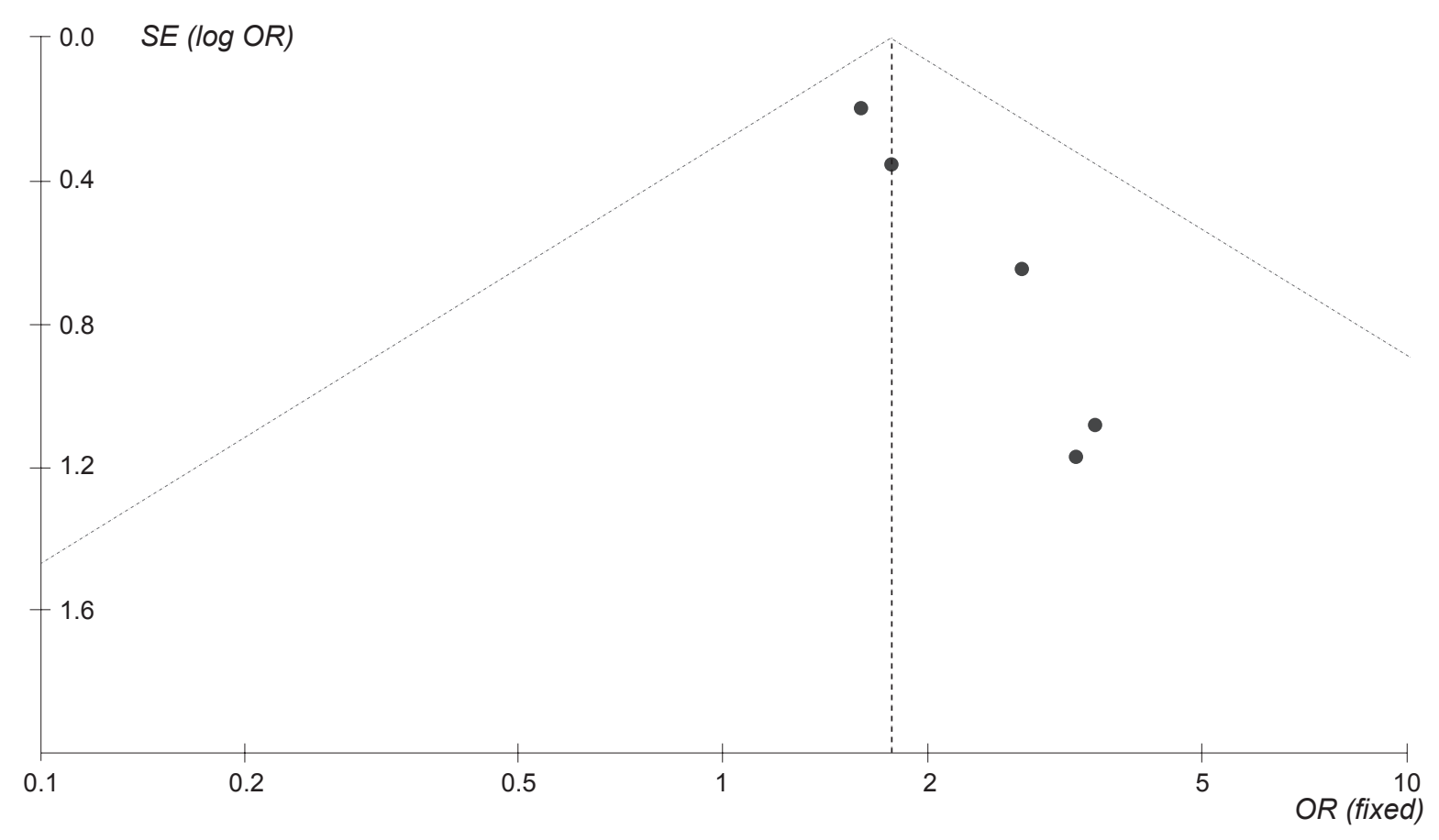

Figure 4 Funnel plot inspection on major adverse cardiovascular events in the long-term trials reveals significant asymmetry which suggests publication bias. Abbreviation: OR, odds ratio.

urinary effects. The relative risk of urinary retention was significantly increased in a pooled analysis (RR 10.9; 95\% CI 1.26-94.9) (Kesten et al 2006). Upper respiratory tract infections were also more common with tiotropium than with placebo (41.1\% vs 37.2\%) (FDA 2002). The observation that dry mouth, constipation, and urinary tract infection occur more frequently with older age suggests that these adverse events represent systemic effects of the drug (FDA 2002). Tiotropium is associated with detectable plasma concentrations, particularly with chronic use. Other factors that can increase systemic exposure are impaired renal function, increasing age, concomitant cimetidine, and cytochrome P450 2D6 poor metabolizers (FDA 2002). It should be noted that patients with urinary problems and glaucoma were excluded in the most clinical trials; therefore, anticholinergic side effects may be more common in a real-world setting. The adverse effects of tiotropium are summarized in Table 1.

\section{Comparison with other bronchodilators}

The tolerability of tiotropium in comparison with ipratropium (Vincken et al 2002), salmeterol (Brusasco et al 2003; Briggs et al 2005), formoterol (van Noord et al 2005), or salmeterol/fluticasone (SFC) combination (Bateman et al 2008; Wedzicha et al 2008) was investigated in randomized clinical trials.

Fewer patients treated with tiotropium than with ipratropium (15.2\% vs $21.2 \%$ ) withdrew from the 1-year study (Vincken et al 2002) but the difference was not statistically significant $(\mathrm{p}=0.08)$. The withdrawal rates were also lower with tiotropium than with salmeterol. The difference was statistically significant in the 6-month trial (15.4\% vs 18.8\%; p < 0.05) (Brusasco et al 2003) but not in the 3-month trial (Briggs et al 2005) (8.8\% vs $12.6 \%$; $\mathrm{p}=0.15)$. Similar proportions of tiotropium and formoterol recipients withdrew from the randomized crossover study (van Noord et al 2005).

The withdrawal rate was similar between tiotropium and SFC in a 6-week trial (Bateman et al 2008. However, in a 2-year randomized control trial, the withdrawal rate was significantly higher with tiotropium compared with SFC (HR 1.29; 95\% CI 1.08-1.54; $\mathrm{p}=0.005$ ) (Wedzicha et al 2008). In this study, more patients treated with tiotropium withdrew from the study because of COPD exacerbation, perceived lack of efficacy, or unwillingness to remain in the study.

There was no statistically significant difference in allcause mortality comparing tiotropium with ipratropium (Vincken et al 2002) or salmeterol (Brusasco et al 2003; Kesten et al 2006). However, mortality was significantly higher with tiotropium than with SFC (6\% vs 3\%; $\mathrm{p}=0.032)$ (Wedzicha et al 2008). The leading causes of death, in order of prevalence, were cardiac, respiratory and neoplastic disorders. The incidence of cardiac death was non-significantly higher with tiotropium than with SFC (3\% vs $1 \%$; $\mathrm{p}=0.09)$. The authors concluded that further studies powered on 
Table I Adverse effects of tiotropium

Severe reactions
Hypersensitivity reaction
Angioedema
Paradoxical bronchospasm
Increased intraocular pressure/glaucoma
Paralytic ileus
Angina pectoris
Stroke
Common reactions (>I\%)
Upper respiratory tract infection, pharyngitis, sinusitis
Dry mouth, throat irritation
Chest pain, tachycardia, palpitations
Urinary tract infection, urinary hesitancy/retention
Dyspepsia, vomiting, constipation, abdominal pain
Edema
Myalgia
Epistaxis
Rash
Candidiasis
Acute angle closure glaucoma, blurred vision, cataract

mortality would be required to confirm these findings since the all-cause mortality was not a primary outcome in the study (Wedzicha et al 2008). It should be kept in mind that this study compared one drug (ie, tiotropium) with a combination therapy with a LABA and an ICS (ie, salmeterol plus fluticasone).

Dry mouth occurred more frequently with tiotropium than with ipratropium $(12.1 \%$ vs $6.1 \% ; \mathrm{p}=0.03)$ (Vincken et al 2002) or with salmeterol ( $8.2 \%$ vs $1.7 \%$; p < 0.05$)$ (Brusasco et al 2003). According to a recent meta-analysis (Barr et al 2006), other anticholinergic adverse events such as constipation, urinary retention and urinary tract infections occurred more frequently with tiotropium than with ipratropium or salmeterol. However, the differences were not statistically significant. The incidence of adverse cardiac events was similar between tiotropium and SFC ( $5 \%$ vs $3 \%$, Wedzicha et al 2008) or salmeterol (Brusasco et al 2003; Singh et al 2008). However, it is unlikely that these studies were sufficiently powered to detect a significant difference in the incidence of cardiac adverse events.

\section{Patient satisfaction, adherence, and quality of life}

In clinical practice, frequent administration creates a problem with drug adherence. Adherence with inhaled medications are generally fair to poor with compliance rates of somewhere between 10\% and 50\% (Rand et al 1995; Breekveldt-Postma et al 2004; Bender et al 2006; Kingsman et al 2007). Once-aday administration with tiotropium is likely to improve compliance compared to multiple daily administration required with other inhaled medications. In a retrospective analysis including 5330 patients in the Netherlands, about $37 \%$ of new users of tiotropium continued treatment for 1 year whereas only $14 \%$ with ipratropium, $13 \%$ with LABA and $17 \%$ with LABA plus ICS remained on the treatment for the same duration (Breekveldt-Postma et al 2007). A Canadian study also showed that patients taking tiotropium had significantly longer persistence at 12 months compared with other inhaled medications including ipratropium, ipratropium plus salbutamol, formoterol, formoterol plus budesonide, salmeterol, and salmeterol plus fluticasone (53\% vs $7 \%$ to $30 \%$; all $\mathrm{p}<0.0001)$ (Cramer et al 2007).

There is a paucity of data on patient satisfaction with long-acting bronchodilators.

\section{Risk benefit analysis of tiotropium}

Tiotropium can improve lung function, reduce symptoms and exacerbations, and improve quality of life with once-daily dosing (Barr et al 2006). Tiotropium also showed a trend toward reduced mortality and induced long-term improvement in the UPLIFT study (Tashkin et al 2008).

Tiotropium is generally well tolerated with dry mouth being the main adverse effect.

Despite recently raised concerns about possible association between inhaled anticholinergics and elevated cardiovascular events, the risk/benefit ratio of tiotropium still appears favorable in symptomatic patients with moderate-to-severe COPD given the favorable safety profile demonstrated in the UPLIFT study. There were fewer cardiovascular events with tiotropium compared with placebo in the UPLIFT study. Our pooled analyses incorporating the UPLIFT study also confirmed the cardiac safety of tiotropium (Figures 1, 3). Respiratory events including COPD-related exacerbations and hospitalizations were also significantly less with tiotropium (RR 0.84; 95\% CI 0.77-0.92) as shown in previous studies (Barr et al 2006; Oba 2007).

One caveat is that cardiac safety database is very limited in high-risk patients such as those with coronary artery disease, heart failure, cardiac arrhythmia, hypoxemia requiring daytime oxygen therapy, and a creatinine $>2.0 \mathrm{mg} / \mathrm{dL}$ since such patients were excluded from phase III clinical trials (Vincken et al 2002; Brusasco et al 2003; Casaburi et al 2005; Niewoehner et al 2005; Dusser et al 2006; 
Tashkin et al 2008). Those patients may be at increased risk of drug-related cardiac events in a real-world setting.

Currently, it is largely clinician and patient preferences as to which inhaled long-acting bronchodilator to be used as the first-line maintenance therapy in symptomatic patients with moderate-to-severe COPD (Qaseem et al 2007; Rabe et al 2007). For example, clinicians may prefer SFC over tiotropium given possible mortality benefit and/or better tolerability with SFC (Calverley et al 2007; Wedzicha et al 2008). Clinicians and patients may elect to use tiotropium over salmeterol if patients are experiencing frequent exacerbations or hospitalizations (Barr et al 2006). Third-party payers may elect tiotropium over salmeterol as a preferred drug in their formulary given more favorable cost-effectiveness ratio with tiotropium (Oba 2007).

\section{Conclusions}

Tiotropium bromide is a long-acting inhaled anticholinergic agent and one of the first-line maintenance therapies in symptomatic patients with moderate-to-severe COPD. Tiotropium is generally well tolerated with dry mouth being the main adverse effect, which is generally not troublesome enough to discontinue the drug. Other adverse effects include constipation, tachycardia, blurred vision, urinary retention and increased intraocular pressure. Despite the recently raised concerns about an excess risk of cardiovascular adverse events with inhaled anticholinergic agents, the risk/benefit ratio of tiotropium appears still favorable given the favorable safety profile demonstrated in the UPLIFT study. However, caution should be advised in patients at high risk for cardiovascular disease given the paucity of data in such patients. The same is true for LABAs in patients with a reactive airway component and ICSs in patients at high risk for pneumonia.

\section{Disclosures}

The authors have no conflicts of interest to disclose.

\section{References}

Anthonisen NR, Connett JE, Enright PL, et al. 2002. Hospitalizations and mortality in the Lung Health Study. Am J Respir Crit Care Med, 166:333-9.

Anthonisen NR, Skeans MA, Wise RA, et al. 2005. The effects of a smoking cessation intervention on 14.5-year mortality: a randomized clinical trial. Ann Intern Med, 142:233-9.

Barnes PJ. 2000. The pharmacological properties of tiotropium. Chest, 117:63S-66.

Barr RG. Management of chronic obstructive pulmonary disease. 2004. JAMA, 291:1066-7; author reply 1067 .

Barr RG, Bourbeau J, Camargo CA, et al. 2006. Tiotropium for stable chronic obstructive pulmonary disease: A meta-analysis. Thorax, 61:854-62.
Bateman ED, van Dyk M, Sagriotis A. 2008. Comparable spirometric efficacy of tiotropium compared with salmeterol plus fluticasone in patients with COPD: a pilot study. Pulm Pharmacol Ther, 21:20-5.

Bender BG, Pedan A, Varasteh LT. 2006. Adherence and persistence with fluticasone propionate/salmeterol combination therapy. J Allergy Clin Immunol, 118:899-904.

Breekveldt-Postma NS, Gerrits CM, Lammers JW, et al. 2004. Persistence with inhaled corticosteroid therapy in daily practice. Respir Med, 98:752-9.

Breekveldt-Postma NS, Koerselman J, Erkens JA, et al. 2007. Enhanced persistence with tiotropium compared with other respiratory drugs in COPD. Respir Med, 101:1398-405.

Briggs DD Jr, Covelli H, Lapidus R, et al. 2005. Improved daytime spirometric efficacy of tiotropium compared with salmeterol in patients with COPD. Pulm Pharmacol Ther, 18:397-404.

Brusasco V, Hodder R, Miravitlles M, et al. 2003. Health outcomes following treatment for six months with once daily tiotropium compared with twice daily salmeterol in patients with COPD. Thorax, 58:399-404.

Calverley PM, Anderson JA, Celli B, et al. 2007. Salmeterol and fluticasone propionate and survival in chronic obstructive pulmonary disease. N Engl J Med, 356:775-89.

Casaburi R, Briggs DD, Jr., Donohue JF, et al. 2000. The spirometric efficacy of once-daily dosing with tiotropium in stable COPD: a 13-week multicenter trial. The US Tiotropium Study Group. Chest, 118:1294-302.

Casaburi R, Kukafka D, Cooper CB, et al. 2005. Improvement in exercise tolerance with the combination of tiotropium and pulmonary rehabilitation in patients with COPD. Chest, 127:809-17.

Casaburi R, Mahler DA, Jones PW, et al. 2002. A long-term evaluation of once-daily inhaled tiotropium in chronic obstructive pulmonary disease. Eur Respir J, 19:217-24.

Celli BR, MacNee W. 2004. Standards for the diagnosis and treatment of patients with COPD: a summary of the ATS/ERS position paper. Eur Respir J, 23:932-46.

Chan CK, Maltais F, Sigouin C, et al. 2007. A randomized controlled trial to assess the efficacy of tiotropium in Canadian patients with chronic obstructive pulmonary disease. Can Respir J, 14:465-72.

Chapman KR. 1990. The role of anticholinergic bronchodilators in adult asthma and chronic obstructive pulmonary disease. Lung, 168:295-303.

COMBIVENT Inhalation Aerosol Study Group. 1994. In chronic obstructive pulmonary disease, a combination of ipratropium and albuterol is more effective than either agent alone. An 85-day multicenter trial. Chest, 105:1411-9.

Covelli H, Bhattacharya S, Cassino C, et al. 2005. Absence of electrocardiographic findings and improved function with once-daily tiotropium in patients with chronic obstructive pulmonary disease. Pharmacotherapy, 25:1708-18.

Cramer JA, Bradley-Kennedy C, Scalera A. 2007. Treatment persistence and compliance with medications for chronic obstructive pulmonary disease. Can Respir J, 14:25-9.

Criner GJ, Sharafkhaneh A, Player R, et al. 2008. Efficacy of tiotropium inhalation powder in african-american patients with chronic obstructive pulmonary disease. COPD, 5:35-41.

Dahl R, Greefhorst LA, Nowak D, et al. 2001. Inhaled formoterol dry powder versus ipratropium bromide in chronic obstructive pulmonary disease. Am J Respir Crit Care Med, 164:778-84.

Disse B, Reichl R, Speck G, et al. 1993. Ba 679 BR, a novel long-acting anticholinergic bronchodilator. Life Sci, 52:537-44.

Donohue JF, Menjoge S, Kesten S. 2003. Tolerance to bronchodilating effects of salmeterol in COPD. Respir Med, 97:1014-20.

Donohue JF, van Noord JA, Bateman ED, et al. 2002. A 6-month, placebocontrolled study comparing lung function and health status changes in COPD patients treated with tiotropium or salmeterol. Chest, 122:47-55.

Dusser D, Bravo ML, Iacono P. 2006. The effect of tiotropium on exacerbations and airflow in patients with COPD. Eur Respir J, 27:547-55.

Ernst P, Gonzalez AV, Brassard P, et al. 2007. Inhaled corticosteroid use in chronic obstructive pulmonary disease and the risk of hospitalization for pneumonia. Am J Respir Crit Care Med, 176:162-6. 
Fishman A, Martinez F, Naunheim K, et al. 2003. A randomized trial comparing lung-volume-reduction surgery with medical therapy for severe emphysema. $N$ Engl J Med, 348:2059-73.

Food and Drug Administration. 2002. Pulmonary-Allergy Drugs Advisory Committee. 2002 Clinical briefing document. Integrated review of safety, NDA, 21-395.

Food and Drug Administration. 2005. FDA Public Health Advisory. Serevent Diskus (salmeterol xinafoate inhalation powder), Advair Diskus (fluticasone propionate and salmeterol inhalation powder), Foradil Aerolizer (formoterol fumarate inhalation powder). Accessed October, 2008.URL: http://www.fda.gov/cder/drug/advisory/ LABA.htm.

Food and Drug Administration. 2008. Early Communication about an Ongoing Safety Review of Tiotropium. Accessed October, 2008.URL: http://www.fda.gov/cder/drug/early_comm/tiotropium.htm.

GlaxoSmithKline. 2005. Clinical trial register for a multicenter, randomized, double-blind,double-dummy, parallel group, 8-week comparison of salmeterol xinafoate versus ipratropium bromide versus salmeterol xinafoate plus ipratropium bromide versus placebo in subjects with chronic obstructive pulmonary disease. Accessed October, 2008. URL: http://www.gsk-clinicalstudyregister.com/files/pdf/2981.pdf.

GlaxoSmithKline. 2005. Clinical trial register for a multicenter, randomized, double-blind,double-dummy, parallel-group, 8-week comparison of salmeterol xinafoate versus ipratropium bromide versus salmeterol xinafoate plus ipratropium bromide versus placebo in subjects with chronic obstructive pulmonary disease. Accessed October, 2008. URL: http://www.gsk-clinicalstudyregister.com/files/pdf/2843.pdf.

Gross NJ, Skorodin MS. 1984. Role of the parasympathetic system in airway obstruction due to emphysema. N Engl J Med, 311:421-5.

Kesten S, Jara M, Wentworth C, et al. 2006. Pooled clinical trial analysis of tiotropium safety. Chest, 130:1695-703.

Krigsman K, Nilsson JL, Ring L. 2007. Refill adherence for patients with asthma and COPD: comparison of a pharmacy record database with manually collected repeat prescriptions. Pharmacoepidemiol Drug Saf, 16:441-8.

Lee TA, Pickard AS, Au DH, et al. 2008. Risk for death associated with medications for recently diagnosed chronic obstructive pulmonary disease. Ann Intern Med, 149(6):380-90.

Mahler DA, Donohue JF, Barbee RA, et al. 1999. Efficacy of salmeterol xinafoate in the treatment of COPD. Chest, 115:957-65.

Medical Research Council Working Party. 1981. Long term domiciliary oxygen therapy in chronic hypoxic cor pulmonale complicating chronic bronchitis and emphysema. Lancet, 1:681-6.

Moita J, Barbara C, Cardoso J, et al. 2008. Tiotropium improves FEV in patients with COPD irrespective of smoking status. Pulm Pharmacol Ther, 21:146-51.

National Collaborating Centre for Chronic Conditions. 2004 Chronic obstructive pulmonary disease. National clinical guideline on management of chronic obstructive pulmonary disease in adults in primary and secondary care. Thorax, 59(Suppl 1):1-232.

Nichol KL, Baken L, Nelson A. 1999. Relation between influenza vaccination and outpatient visits, hospitalization, and mortality in elderly persons with chronic lung disease. Ann Intern Med, 130:397-403.

Niewoehner DE, Rice K, Cote C, et al. 2005. Prevention of exacerbations of chronic obstructive pulmonary disease with tiotropium, a once-daily inhaled anticholinergic bronchodilator: a randomized trial. Ann Intern Med, 143:317-26.
Nocturnal Oxygen Therapy Trial Group. 1980. Continuous or nocturnal oxygen therapy in hypoxemic chronic obstructive lung disease: a clinical trial. Nocturnal Oxygen Therapy Trial Group. Ann Intern Med, 93:391-8.

Oba Y. 2007. Cost-effectiveness of long-acting bronchodilators for chronic obstructive pulmonary disease. Mayo Clin Proc, 82:575-82.

Pauwels RA, Buist AS, Calverley PM, et al. 2001. Global strategy for the diagnosis, management, and prevention of chronic obstructive pulmonary disease. NHLBI/WHO Global Initiative for Chronic Obstructive Lung Disease (GOLD) Workshop summary. Am J Respir Crit Care Med, 163:1256-76.

Powrie DJ, Wilkinson TM, Donaldson GC, et al. 2007. Effect of tiotropium on sputum and serum inflammatory markers and exacerbations in COPD. Eur Respir J, 30:472-8.

Qaseem A, Snow V, Shekelle P, et al. 2007. Diagnosis and management of stable chronic obstructive pulmonary disease: a clinical practice guideline from the American College of Physicians. Ann Intern Med, 147:633-8.

Rabe KF, Hurd S, Anzueto A, et al. 2007. Global strategy for the diagnosis, management, and prevention of chronic obstructive pulmonary disease: GOLD executive summary. Am J Respir Crit Care Med, 176:532-55.

Rand CS, Nides M, Cowles MK, et al. 1995. Long-term metered-dose inhaler adherence in a clinical trial. The Lung Health Study Research Group. Am J Respir Crit Care Med, 152:580-8.

Rennard SI, Anderson W, ZuWallack R, et al. 2001. Use of a long-acting inhaled beta2-adrenergic agonist, salmeterol xinafoate, in patients with chronic obstructive pulmonary disease. Am J Respir Crit Care Med, 163:1087-92.

Salpeter SR, Ormiston TM, Salpeter EE. 2004. Cardiovascular effects of beta-agonists in patients with asthma and COPD: a meta-analysis. Chest, 125:2309-21.

Sestini P, Renzoni E, Robinson S, et al. 2002. Short-acting beta 2 agonists for stable chronic obstructive pulmonary disease. Cochrane Database Syst Rev: CD001495.

Singh S, Loke YK, Furberg CD. 2008. Inhaled anticholinergics and risk of major adverse cardiovascular events in patients with chronic obstructive pulmonary disease: a systematic review and meta-analysis. JAMA, 300:1439-50.

Tashkin DP, Celli B, Senn S, et al. 2008. A 4-year trial of tiotropium in chronic obstructive pulmonary disease. N Engl J Med, 359:1543-54.

van Noord JA, Smeets JJ, Custers FL, et al. 2002. Pharmacodynamic steady state of tiotropium in patients with chronic obstructive pulmonary disease. Eur Respir J, 19:639-44.

van Noord JA, Aumann JL, Janssens E, et al. 2005. Comparison of tiotropium once daily, formoterol twice daily and both combined once daily in patients with COPD. Eur Respir J, 26:214-22.

Verkindre C, Bart F, Aguilaniu B, et al. 2006. The effect of tiotropium on hyperinflation and exercise capacity in chronic obstructive pulmonary disease. Respiration, 73:420-7.

Vincken W, van Noord JA, Greefhorst AP, et al. 2002. Improved health outcomes in patients with COPD during 1 yr's treatment with tiotropium. Eur Respir J, 19:209-16.

Voshaar T, Lapidus R, Maleki-Yazdi R, et al. 2008. A randomized study of tiotropium Respimat Soft Mist inhaler vs. ipratropium pMDI in COPD. Respir Med, 102(1):32-41.

Wedzicha JA, Calverley PM, Seemungal TA, et al. 2008. The prevention of chronic obstructive pulmonary disease exacerbations by salmeterol/ fluticasone propionate or tiotropium bromide. Am J Respir Crit Care Med, 177:19-26. 